\title{
REPRESENTAÇÕES SOCIAIS DAS PRIMÍPARAS ADOLESCENTES SOBRE O CUIDADO MATERNO AO RECÉM-NASCIDO ${ }^{1}$
}

\author{
Emanuele Folle ${ }^{2}$ \\ Lorena Teresinha Consalter Geib ${ }^{3}$
}

Folle E, Geib LTC. Representações sociais das primíparas adolescentes sobre o cuidado materno ao recém-nascido. Rev Latino-am Enfermagem 2004 março-abril; 12(2):183-90.

Com o objetivo de analisar as representações sociais das adolescentes primíparas sobre o cuidado materno ao recém-nascido no âmbito domiciliar, realizou-se esse estudo qualitativo. Participaram oito adolescentes, com filhos primogênitos recém-nascidos. Os dados coletados em suas residências, com técnica projetiva e entrevistas semi-estruturadas, foram analisados à luz da teoria das representações sociais, evidenciando que as adolescentes representam o cuidado materno nos núcleos figurativos de afeição, integração familiar e realização materna. Simbolicamente, o cuidado materno ancora-se no surgimento da família, na perenidade dos sentimentos e no compromisso com o desenvolvimento psicomotor da criança. As primíparas adolescentes valorizam mais o ganho de pertencimento a uma família do que as perdas acarretadas pela maternidade precoce. O cuidado materno é um exercício conflitivo, ora representando o status de ser adulta e responsável, ora denotando a insegurança, o despreparo e a infantilidade, que afetam o atendimento ao recém-nascido.

DESCRITORES: adolescente; comportamento materno

\section{SOCIAL REPRESENTATIONS OF TEENAGERS WITH THEIR FIRST-BORN CHILD ON MATERNAL CARE TO NEWBORNS}

This qualitative study aimed to analyze the social representation of teenagers who had their first child and about maternal care to newborns in the home environment. Participants were eight teenagers with their newborns. Data were collected at their homes by means of projective techniques and semi-structured interviews. Analysis was based on social representation theory, demonstrating that the teenagers represent maternal care in figurative centers of affection, family integration and maternal fulfillment. The maternal care is symbolically anchored in the appearance of a family, in the continuum of feelings and in the commitment to the psychomotor progress of the child. The teenagers who had their first child gave more value to belonging to a family than to the losses resulting from early motherhood. Maternal care is a conflictive exercise. On the one hand, it represents the status of being an adult and responsible but, on the other, it marks insecurity, lack of preparation and immaturity, which affect care to the newborn.

DESCRIPTORS: adolescent; maternal behavior

\section{REPRESENTACIONES SOCIALES DEL CUIDADO MATERNO AL RECIÉN NACIDO EN ADOLESCENTES PRIMIGESTANTES}

Con el objetivo de analizar las representaciones sociales de las adolescentes primigestantes a cerca del cuidado materno al recién nacido en el ámbito domiciliar, se realizó este estudio cualitativo. Participaron ocho adolescentes, con hijos recién nacidos. Los datos recolectados en sus residencias, con técnicas de proyección y entrevistas semiestructuradas, fueron analizados en la luz de la teoría de las representaciones sociales, poniendo en evidencia que las adolescentes representan el cuidado materno en los núcleos figurativos de afecto, integración familiar y realización materna. Simbólicamente, el cuidado materno esta basado en la formación de la familia, en la perennidad de los sentimientos y en el compromiso con el desarrollo psicomotor del niño. Las primíparas adolescentes valorizan más la formación de una familia, que las pérdidas consecuentes de la maternidad precoz. El cuidado materno es un ejercicio conflictivo, a veces representando un status de ser adulta y responsable, otras mostrando la inseguridad, la falta de preparación y la infantilidad, que afectan la atención al recién nacido.

DESCRIPTORES: adolescente; conducta materna

\footnotetext{
${ }^{1}$ Trabalho desenvolvido na disciplina de Iniciação Científica em Enfermagem do Curso de Enfermagem da Universidade de Passo Fundo; ${ }^{2}$ Enfermeira da Secretaria Municipal de Saúde do município de Passo Fundo; ${ }^{3}$ Mestre em Enfermagem, Professor Titular da Universidade de Passo Fundo, e-mail: Iorena@upf.tche.br
} 
INTRODUÇÃO

O cuidado materno constitui um conjunto de ações biopsicossocioambientais que permitem à criança desenvolver-se bem. Além de sentir-se rodeada de afeição, a criança precisa de um potencial de cuidados e providências a serem tomados: o sono tranqüilo, a alimentação, a higiene e outros. Reconhecer e saber interpretar corretamente os sinais que o recém-nascido emite é imprescindível para a sua saúde e o seu bemestar.

Os fatores que impulsionam o cuidado ao recémnascido são as preocupações maternas primárias, novas responsabilidades e amadurecimento pessoal. Uma primípara adolescente pode estar se sentindo muito jovem ou emocionalmente imatura para assumir a maternidade. Dentre suas inquietações, é comum persistirem aquelas que a levaram à gravidez precoce como a desilusão, 0 mau uso ou a falta de contracepção, as experiências prematuras de perdas, a separação dos primeiros cuidadores, o divórcio dos pais ou a morte de um familiar. A esses fatores somam-se ainda a rebeldia, a solidão, a baixa auto-imagem e a fragilidade de vínculo com as próprias mães ${ }^{(1)}$.

A primiparidade precoce repercute, assim, na vida pessoal, familiar, social e educacional da adolescente. Do ponto de vista pessoal, a adolescente defronta-se com as alterações corporais provocadas pela gestação, que afetam a sua auto-imagem e auto-estima. Esse estado de autodepreciação é agravado pela insegurança no cuidado com seu bebê, decorrente da sua inexperiência e imaturidade. Para superar essa dificuldade é comum à mesma permanecer vivendo com a família. A maternidade, nessas circunstâncias, gera mudança na dinâmica familiar, interferindo no padrão de sono, repouso, alimentação, lazer, entre outros. Além disso, em alguns casos, acarreta sobrecarga financeira, que priva a adolescente de investimentos pessoais. Entre esses investimentos, está o processo de educação, freqüentemente interrompido, gerando atraso na vida estudantil e distanciamento do grupo de convivência.

A conscientização de que a maternidade não é apenas um ato biológico-reprodutivo, mas um fenômeno social, torna necessária a compreensão da vida cotidiana das mães adolescentes. Dessa forma, junto com elas, buscamos representar a maternidade do primeiro filho, repensá-la, torná-la familiar e convertê-la em conhecimento científico elaborado e compartilhado a partir dessas representações sociais, possibilitando a construção de um referencial explicativo, que possa contribuir para a avaliação e acompanhamento da mãe adolescente, assim como para a melhoria da assistência à saúde da mulher e da criança.

Esse universo constituído pelo ambiente, pelas informações que nele circulam e pelas pessoas das relações da adolescente servem para que ela, enquanto sujeito social, apreenda os acontecimentos da vida cotidiana. Esse conhecimento apreendido a partir das experiências comuns e situado na fronteira entre 0 psicológico e o social é elaborado no senso comum e constitui uma maneira específica de conhecer o mundo e comunicar-se ${ }^{(2)}$. É, portanto, um processo sóciocognitivo, que influencia os comportamentos adotados pelas primíparas precoces, pois elas adotam os comportamentos resultantes do modo como elas representam socialmente a maternidade e do significado que essa assume em suas vidas. Esse modo de conhecimento, que corresponde ao universo consensual, é chamado de representação social ${ }^{(3)}$. Pode ser compreendido como "um conjunto de conceitos, proposições e explicações originado na vida cotidiana no curso de comunicações interpessoais. "As representações sociais são o equivalente, em nossa sociedade, aos mitos e sistemas de crenças das sociedades tradicionais, podem também ser vistas como a versão contemporânea do senso comum $^{\prime(3)}$. São modalidades de conhecimento "que articulam-se no dia-a-dia, de acordo com dois processos formadores fundamentais: a objetificação e a ancoragem" ${ }^{\text {"(3) }}$. A objetificação "faz com que se torne real um esquema conceptual, transformando o que era abstrato em elemento concreto. É o processo que dá materialidade às idéias, tornando-as objetivas, concretas, palpáveis. Torna o abstrato em concreto $(. . .)^{n(3)}$. Para realizar-se a objetificação são necessárias três etapas: a) construção seletiva da realidade: corresponde à forma específica utilizada pelos indivíduos e grupos sociais para apropriarse dos conhecimentos acerca de determinado objeto; b) esquematização flutuante à formação de um núcleo figurativo - "é a formação de uma estrutura de imagem que reproduz uma estrutura figurativa ou conceitual” ${ }^{(4)} ; c$ ) naturalização: é a transformação do abstrato em concreto. Os pensamentos convertidos em figuras são transportados para dentro da realidade.

Dessa forma, a objetificação fornece as 
ferramentas para a ancoragem. A ancoragem é o processo que "permite compreender a forma como os elementos contribuem para exprimir e constituir as relações sociais" ${ }^{\text {"(4) }}$, ou seja, a ancoragem contribui para dar sentido aos acontecimentos, pessoas, grupos e fatos sociais a partir da rede de significados oferecidos pelas representações sociais. Dessa forma, transforma o objeto estranho em algo familiar.

O fenômeno maternidade e adolescência, além de estar intimamente relacionado com os aspectos de maturação biológica e psicológica, está sob efeito de outros fatores importantes como os ambientais e sociais. Portanto, ao objetivar-se a compreensão do fenômeno, urge conhecer o mundo social dessas jovens e apreender como vivem no seu espaço de relacionamentos. Neste caso específico, com o objetivo de analisar as representações sociais sobre o cuidado materno ao recémnascido no âmbito domiciliar, elaborado pelas primíparas adolescentes a partir do senso comum, consideramos a seguinte recomendação ${ }^{(5)}$ : “... as representações sociais devem ser estudadas articulando elementos afetivos, sociais, integrando a cognição, a linguagem e a comunicação, as relações sociais que afetam as representações sociais e a realidade social e ideativa sobre a qual elas intervêm".

Acreditamos que o desenvolvimento das representações sociais das primíparas precoces sobre sua maternidade, contribua para o estabelecimento de uma identidade materna, muitas vezes prejudicada pelas condições biopsicossociais inerentes à adolescência e pela fragilidade de suporte social para o auto e heterocuidado no período pós-natal.

\section{METODOLOGIA}

Esta pesquisa de abordagem qualitativa na linha da representação social foi desenvolvida no domicilio das adolescentes no município de Passo Fundo, RS. Participaram do estudo oito primíparas localizadas a partir dos prontuários de um hospital geral do município de Passo Fundo, RS, com idades entre 14 e 19 anos, que deram à luz a seus filhos no mês de agosto de 2002, e aceitaram participar do estudo através do Termo de Consentimento Informado, assinado por elas próprias e por seus responsáveis legais.

Os dados foram coletados nos meses de agosto e setembro de 2002, com a utilização das seguintes técnicas: a) colagens para a expressão dos pensamentos e sentimentos da primípara adolescente sobre o cuidado materno, permitindo a objetificação (núcleo figurativo). Para a ancoragem foi solicitado às participantes que expressassem verbalmente os conhecimentos a respeito do fenômeno, "transformando a imagem em linguagem, dando-Ihes uma explicação, um contexto inteligível ao objeto"(3). Dessa forma, obtivemos o núcleo simbólico. Essa atividade durou uma hora e meia e foi realizada individualmente, devido à dificuldade de reunir as participantes em grupo; $b$ ) entrevista semi-estruturada, com gravação previamente consentida.

Os dados foram analisados à luz do referencial teórico das representações sociais, seguindo esses passos metodológicos ${ }^{(3)}: 1^{\circ}$ momento - objetificação: através do processo de tornar real algo pensado, através da colagem, chegamos ao processo de formação dos núcleos figurativos, correspondentes aos temas que possuem a propriedade de serem representados e que expressam a concretude da idéia; $2^{\circ}$ momento ancoragem: corresponde à interpretação das participantes sobre o material produzido nas colagens, atribuindo um significado para a imagem por elas produzida. Nesse momento, colhemos as simbolizações e percepções a partir dos relatos verbais sobre os conhecimentos a respeito do fenômeno; na seqüência, foram identificados os temas que representam esse conhecimento, constituindo os núcleos simbólicos; $3^{\circ}$ momento validação pelas participantes das configurações dadas pelo pesquisador à representação social do cuidado materno, confirmando ou não a identificação de núcleos dessa representação. Embora previsto, esse momento não pôde ser realizado pela dificuldade de reunir as adolescentes em grupo; $4^{\circ}$ momento - sistematizamos as informações, agrupando os temas de destaque por classificação em núcleos figurativos e núcleos simbólicos. Posteriormente, à luz do referencial teórico, estabelecemos a ancoragem sobre a representação social das participantes sobre o cuidado materno ao recém-nascido.

As entrevistas, transcritas na íntegra, foram submetidas à análise de conteúdo, adotando-se a técnica temática ${ }^{(6)}$.

Este estudo observou as diretrizes da Resolução 196/96 do Conselho Nacional da Saúde do Ministério da Saúde e do Código de Ética dos Profissionais de Enfermagem, tendo sido aprovado pelo Comitê de Ética em Pesquisa da Universidade de Passo Fundo. 
DISCUSSÃO E ANÁLISE DOS DADOS

No que diz respeito aos núcleos figurativos 0 cuidado materno ao recém-nascido foi objetifiticado ${ }^{(3)}$ numa situação idealizada e distanciada da realidade psicossocial das adolescentes. O conteúdo projetado nas figuras, em alguns casos, era diametralmente oposto àquilo que se podia constatar no contexto de vida da meninamãe, como no caso de A1. Vivendo em uma vila periférica, num contexto de privações, com espaço domiciliar exíguo, dividido com doze pessoas e marido detento na FEBEM, por sérios desentendimentos com sua própria mãe, essa adolescente realizou as colagens utilizando figuras com forte conotação de união e harmonia familiar, evidenciando sempre a figura paterna. Esses elementos contrastam com o contexto de vida dessa adolescente, em cuja família a figura paterna estava ausente e nenhum de seus membros exercia atividades remuneradas. Nessas circunstâncias de carência financeira, de moradia e de afeto, a adolescente projeta na maternidade o resgate da esperança na vida, por meio da expressão do cuidado materno. A idealização da participação paterna no cuidado do recém-nascido difere da representação social atribuída ao homem, que é de provedor, dele não se esperando o desempenho de tarefas domésticas e de cuidados com as crianças, tarefas tidas como essencialmente femininas e domésticas e aprendidas nas regras sociais sobre as próprias identidades masculina e feminina ${ }^{(7)}$.

Outro aspecto significativo na representação figurativa foi o fato da adolescente colar todas as figuras às margens do papel, como se estivesse saindo da realidade (delimitada pelo papel) para o espaço ilusório onde estava a afeição, o amor .... aquilo que "deveria" ser o cuidado materno.

A mesma situação de idealização é reproduzida por outras adolescentes, cuja inserção social assemelhase àquela de A4. Percebe-se a aceitação social do nascimento do bebê, independentemente da idade materna, refletida na interação familiar harmônica, que favorece o sentimento de realização pessoal pela maternidade, o qual, por sua vez, é motivo de comemoração e celebração. Do ponto de vista das adolescentes, o cuidado materno exercido precocemente tem impacto positivo em suas vidas. Poderia essa representação positiva ser temporária e estar relacionada ao fato do bebê ainda constituir-se em novidade? Essa representação permaneceria a mesma no decorrer do processo de crescimento e desenvolvimento da criança, quando aumentam as exigências de cuidado materno? $\mathrm{O}$ amparo social recebido pela adolescente no período puerperal estaria mascarando o enfrentamento da maternidade e, com isso, evidenciando-a como uma experiência gratificante? O que simbolizam esses núcleos figurativos?

Para responder a essa última questão, olhemos para os significados que as adolescentes atribuíram às figuras selecionadas na técnica de colagem, examinando as categorias do núcleo simbólico. As primíparas adolescentes ancoram o cuidado materno ao recémnascido no surgimento da nova família. Uma família com capacidade de imortalização dos sentimentos positivos e de comprometimento afetivo e social na condição de provedora e educadora da criança. Tudo isso parece melhor representado na categoria da realidade ao sonho, pois elas parecem projetar os seus próprios anseios de cuidado, num processo de preenchimento daquelas lacunas psicossociais deixadas ao longo da vida, que clamam por dedicação, amor eterno, educação, carinho ... sintetizado num cuidado ilusório transferido ao recém-nascido, símbolo concreto do (re)nascer.

Elas parecem reviver um descuido do cuidado, uma vez que elas próprias foram privadas de maternagem e reproduzem, assim, esse modelo de carência no cuidado ilusório de uma futura família. A família representada nas imagens como pai-mãe-filho(s) não é a família com a qual a realidade as brindou, haja vista que das oito adolescentes somente três possuíam a família nuclear dos sonhos externados nos núcleos figurativos. Ressalta-se que essas três adolescentes viviam nas famílias extensivas, isto é, constituídas pela família nuclear mais os avós e tios do bebê, o que pode explicar o desejo de pertencer a uma família tal qual a projetada nas colagens.

Do ponto de vista antropológico, a família é definida como uma unidade grupal onde se desenvolvem três tipos de relações pessoais: aliança (casal), filiação (pais/filhos) e consangüinidade (irmãos), com o objetivo de preservar a espécie, nutrir e proteger a descendência e fornecer-Ihe condições para a aquisição de suas identidades pessoais e dos valores éticos, estéticos, religiosos e culturais. Essas são as características da família nuclear do mundo ocidental de hoje ${ }^{(8)}$, que representam o sonho das adolescentes deste estudo. Essas, tendo cumprido as etapas do desenvolvimento da infância e sentindo o amadurecimento proporcionado pela 
maternidade, sentem agora a necessidade de se tornarem independentes de seus pais num movimento natural de separação e individuação em relação à sua família de origem $^{(9)}$.

No que tange ao cuidado materno, a família tradicional não é o único cenário sadio em que pode evoluir o desenvolvimento da criança. O importante é considerar que o bebê, ao nascer, está equipado com mecanismos de interação e intercâmbio social, por isso é dever da família oferecer à criança, independente do ambiente, elementos que incluam: relação amorosa, oportunidades para a vinculação, a continuidade da assistência e carinho, a estimulação adequada e relacionamento sólido com uma pessoa $^{(10)}$.

As representações sociais advindas das falas produzidas durante as entrevistas puderam ser categorizadas como segue.

O bebê como fonte de felicidade, amadurecimento saudável e apropriação legítima

Para essas adolescentes o recém-nascido representa uma gama de sentimentos positivos, a extensão de sua própria vida e o responsável direto tanto pela motivação renovada e crescimento psicológico, quanto pelo processo de amadurecimento materno, que as fazem perceber o compromisso da maternidade, como revelam as seguintes falas: Para mim é bom. Parece que amadureci mais, tenho mais compromisso agora. Antes não tinha vontade de estudar. Agora eu estou estudando mais... (A4) .... Muda bastante em relação aos bebês que eu cuidava, porque eu cuidava e de noite eu entregava. Agora este eu sei que é meu (A7).

O recém-nascido representa um ganho afetivo capaz de qualificar o processo de desenvolvimento pessoalsocial da adolescente, tornando-a mais amadurecida e resgatando sua motivação para os estudos.

$\mathrm{Na}$ transição entre a infância e a vida adulta é necessário que o adolescente vá se desligando de suas experiências infantis por meio dos seguintes lutos fundamentais: o luto pelo corpo infantil, o luto pelo papel e pela identidade infantil e o luto pelos pais da infância. Esse processo é lento e não pode ser acelerado nem pelas modificações da puberdade, nem pelo meio social, pois caso o indivíduo seja chamado a assumir precocemente uma identidade adulta, ele sentirá esse processo ainda mais ameaçador e conflitivo do que já é, podendo ocasionar prejuízo ao seu desenvolvimento psíquico por não ter tido tempo para internalizar as mudanças ocorridas ${ }^{(11)}$.
Acreditamos que a primiparidade precoce insere-se nesse contexto. $\mathrm{O}$ fato dos dados deste estudo terem sido coletados no período puerperal, quando a adolescente vivenciava suas primeiras experiências como mãe, parecem ter contribuído para a percepção de amadurecimento, que Ihe conferia uma sensação mais adulta e mais comprometida.

Contudo, a repercussão desse amadurecimento no desenvolvimento emocional necessitaria ser acompanhada pelos profissionais de saúde. O enfermeiro, em especial, em sua preocupação com a construção de um modelo de educação em saúde e assistência, que atenda as peculiaridades da população, deve promover o atendimento integral da adolescente com ações orientadas para a dimensão psicossocial, nas quais se inserem as questões do desenvolvimento evolutivo acima discutidas e que interferem no processo maturativo do indivíduo. Dessa forma, poderá contribuir para a indissociabilidade dos aspectos biológicos, psicológicos, sociais e culturais, que conferem unidade ao fenômeno da adolescência.

A motivação para a retomada dos estudos pode ser creditada ao bebê e a tudo o que ele representa, especialmente por ter sido considerado como fonte de felicidade. Em termos de representações sociais é importante destacar que o ambiente interfere na avaliação que a adolescente faz da gravidez e da maternidade, visto que, no seu círculo de relações, a gestação na adolescência é comum e o nascimento é encarado com uma conotação positiva, traduzida pela expressão "ganhar um nenen". Para a adolescente, portanto, a maternidade, independentemente da fase evolutiva em que ocorra, tem uma representatividade social positiva. Tornar-se mãe propicia uma vivência humana com a representação social de cuidar e socializar a criança. Muitas vezes, no entanto, o cuidado ao bebê é realizado por outra mulher na ausência da mãe biológica. Nesses casos, como se caracteriza o cuidado ao recém-nascido?

O sentimento de pertença diferencia o cuidado materno daquele cuidado dispensado a outras crianças no exercício das atividades ocupacionais. Esse aspecto foi destacado por A7 ao expressar que o cuidado ao seu bebê é diferente do cuidado que prestava aos bebês na condição de babá. Ao afirmar este eu sei que é meu, a adolescente deixa claro não só a apropriação legítima de seu bebê, como imprime ao cuidado materno o traço do pertencimento, que o diferencia do cuidado profissionalizado. Quando a mãe cuida de seu bebê, alimentando-o, higienizando-o e aquecendo-o, ela atribui 
significado à sua ação. Ao atribuir esse significado ela investe uma energia afetiva, que é dirigida diretamente para o bebê. Por outro lado, quando uma babá cuida do mesmo bebê, a relação cuidador-bebê torna-se permeada por uma série de fatores de mediação como salário, técnica, oposição entre o que ela quer e/ou acredita que deve fazer e as determinações da mãe, entre outras ${ }^{(12)}$. Portanto, quando uma babá está cuidando de uma criança esses fatores estão se interpondo na relação de cuidado, impedindo que o vínculo afetivo com a criança seja completo, pois acima de ser uma relação afetiva é uma profissionalização de cuidado que impõe uma tensão entre vincular-se versus não-vincular-se. Essa profissionalização, na fala de A7, fica evidenciada também quando afirma ...eu cuidava e de noite eu entregava, ou seja, o cuidado tinha aprazamento, e pressupunha a interrupção da afetividade. Dessa forma, a lógica do cuidado não é a mesma lógica do trabalho ${ }^{(12)}$, pois enquanto a primeira engloba a subjetividade, a segunda orienta-se pela objetividade.

A primiparidade precoce ancorada na experiência planejada e isenta de preconceito

Para duas das oito adolescentes, a maternidade precoce resultou de decisão consciente e planejada. Elas elaboraram o seu projeto de vida com a inclusão da gravidez e sentiam-se felizes cumprindo o seu papel social de mães. Suas aspirações reprodutivas rechaçavam o preconceito com a idade.

É no âmbito da sociedade que a adolescente define o seu modo de vida e constrói a sua estrutura psicoemocional. Em relação ao comportamento reprodutivo, a maternidade insere-se no prolongamento da transição da adolescência para a independência e pode constituir um mecanismo adotado por essa adolescente para se valorizar, especialmente quando se sente desrespeitada pelos pais. Nessas circunstâncias, a adolescente pode buscar no papel de mãe o status de autoridade e poder, pertinentes ao mesmo. Engravidar, portanto, além de ser um projeto de vida, pode representar uma forma de resistência à autoridade do adulto. Nas classes sociais menos favorecidas a sensação de deter esse poder possibilita à adolescente o resgate da esperança na possibilidade de viver e ser feliz e de "compensar a imagem do adolescente imaturo e dependente através da função materna socialmente

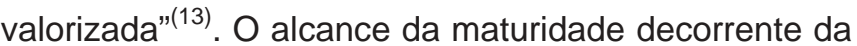

aceitação de novos papéis sociais confere-lhe o status adulto desejado. Por isso, reconhecendo-se como sujeito da sua história pessoal e social, a adolescente repudia atitudes preconceituosas como manifesta $\mathrm{A} 4$ : ....Eu não tenho preconceito. Eu acho que o que interessa é gostar do filho. Nessa afirmação ela defende a maternidade em qualquer etapa da vida, sublinhando o principio do respeito aos adolescentes e assinalando que a primiparidade precoce nem sempre é indesejada.

A primiparidade precoce ancorada no erro, arrependimento e medo

Para a maioria das participantes, no entanto, a primiparidade precoce representou um erro, cujo preço está sendo pago com arrependimento e medo. Pesam sobre a jovem mãe as concepções da gravidez na adolescência como um problema social associado a aspectos negativos como abandono da escola, dificuldade para conseguir emprego, baixo peso dos bebês ao nascer e outros que, somados aos adjetivos pejorativos associados à gravidez como não planejada, indesejada, precoce .... contribuem para fortalecer a crença de que a gravidez na adolescência é socialmente inaceitável ${ }^{(14)}$. Com esses elementos, a adolescente elabora a representação social da primiparidade precoce como um evento a priori indesejado e cercado de privação. Livrá-la do arrependimento e do medo requer dos profissionais da saúde intervenções "menos coercitivas e legitimamente apoiadas na escuta e no dialogo"(14) que possam contribuir para a promoção da saúde psicossocial, constituinte fundamental da sua qualidade de vida.

O cuidado materno ancorado na dificuldade: a confusão de papéis

A dificuldade é a tônica da representação social do cuidado materno. Para minimizá-la a adolescente recorre ao apoio de seu grupo familiar e social e acaba transferindo, geralmente à avó, o exercício do cuidado materno, como revela esta fala: Desde que ela nasceu a minha mãe está me ajudando, é muito difícil de cuidar.... (A3).

A transferência de papéis, decorrente do exercício efetivo da maternidade pela avó, acaba colocando a adolescente na condição de irmã do filho, aumentando ainda mais a dificuldade bastante presente nessa etapa evolutiva: a construção da identidade. Pressionada entre uma infância que sente findar e uma fase adulta precipitada 
pela gravidez, a adolescente declara-se pouco competente para assumir o cuidado materno. Só que ao deixar-se substituir pela própria mãe no desempenho de um papel social que é seu, defronta-se também com a confusão de papéis. Para que ela possa caminhar em direção à resolução de identidade e aceitar o novo papel social é preciso valorizar a família "enquanto espaço essencial à produção da identidade social”,(15) e ajudar a adolescente a atravessar bem essa fase do desenvolvimento emocional, permitindo-lhe assumir, gradativamente, o cuidado materno. É recomendável que médicos e enfermeiras deixem "a cargo da mãe aquilo que ela é capaz de fazer sozinha”(16), considerando-se que "a mãe humana pode adaptar-se às necessidades de seu bebê neste estágio inicial, pois neste período ela não tem nenhum outro interesse" ${ }^{\text {(16) }}$. O cuidado materno facilita os processos de maturação do recémnascido, da mesma forma como a descontinuidade desse cuidado causa-Ihe quebras de adaptação. Diante disso, o trabalho do profissional de saúde pode ser dirigido à avó, não para que ensine a mãe como ser mãe, mas para permitir o estabelecimento das relações interpessoais entre o bebê e sua mãe, sem esquecer que uma primípara muito jovem, ou que foi uma criança carente em sua história inicial, terá muita dificuldade em cuidar sozinha de seu bebê, exatamente da maneira que ela própria precisa ser cuidada. Nesses casos, a perda do apoio do grupo familiar ou social poderá acarretar sérias dificuldades. Da dependência absoluta pode-se caminhar gradualmente para a independência, numa atitude de inclusão da adolescente no cuidado ao recém-nascido, inclusão essa que "pode ser convenientemente chamada de amor"(16) $\mathrm{e}$ que tem o potencial de mudar a sua representação social sobre o cuidado materno.

O desafio do cuidado materno: acalmar, alimentar e lidar com o ciúme e a doença

Os primeiros dias de convívio com o recémnascido em casa são desafiadores para a família. Um dos grandes desafios é compreender e responder ao comportamento do bebê, especialmente quando esse se expressa pelo choro. A sensação de incapacidade para acalmar a criança, nesses momentos, é apontada pelas adolescentes como uma dificuldade no exercício do cuidado materno: ...acalmar ela quando ela está muito braba (A3). ...Para acalmar ele, porque às vezes é difícil, ele chora (A4). Para outras adolescentes, a dificuldade ocorre à noite ...tem que dar de mamá, às vezes eu não quero ... de noite eu só quero dormir (A6). Outras atribuem à doença da criança a dificuldade para cuidá-la: Quando ele tá meio doentinho, porque eu não sei o que ele tem (A5). O ciúme de que outros possam segurar o bebê também é mencionado por uma das adolescentes.

São todas situações cotidianas e comportamentos sociais comuns dos recém-nascidos, que ao denotar fome, sono, desconforto ... desencadeiam outros comportamentos sociais nos pais: embalar, alimentar, trocar ... num ritmo de interação social a serviço da regulação fisiológica. Esses comportamentos também evidenciam que os bebês "possuem uma vida subjetiva muito ativa, cheia de paixões e confusões mutáveis"(16), os quais constituem a sua experiência social. A dificuldade alegada pelas adolescentes para o enfrentamento desses desafios pode estar relacionada ao pouco tempo de convívio com o filho, uma vez que os dados foram coletados entre o $15^{\circ}$ e o $28^{\circ}$ dias de vida, fase crucial da adaptação à nova dinâmica familiar.

\section{CONSIDERAÇÕES FINAIS}

Nas relações sociais estabelecidas na família e no seu grupo de convivência, as adolescentes constroem e projetam as representações e expectativas que orientam o seu modo de ser. Na condição de primíparas, projetam a aceitação social da maternidade precoce e sua esperança no surgimento de uma família unida e harmônica, que possa suprir suas próprias lacunas socioafetivas. O novo status de mãe para algumas confere um sentimento de realização pessoal; para outras, de arrependimento e medo.

O cuidado materno é um exercício difícil e conflitivo, ora representando o alcance da maturidade e da apropriação do filho, ora confrontando-a com a insegurança, o despreparo, a dependência, a infantilidade e, principalmente, com o conflito de identidade, que a faz perceber-se pouco competente como cuidadora do bebê.

A travessia de uma situação de dependência para a de independência no cuidado materno, requer escuta e diálogo dos profissionais de saúde e sua mediação no favorecimento à participação gradativa e segura da adolescente no cuidado ao recém-nascido, para que ela possa superar o conflito de papéis mãe/filha e construir sua identidade pessoal e materna. 


\section{REFERÊNCIAS BIBLIOGRÁFICAS}

1. Raphael-Leff J. Gravidez: a história interior. Porto Alegre (RS): Artes Médicas; 1997.

2. Escudeiro CL, Silva ICM. Adoçando o fel do pesquisar: a doce descoberta das representações sociais. Rio de Janeiro (RJ): Escola de Enfermagem Anna Nery/UFRJ;1997.

3. Padilha MICS. Representações sociais: aspectos teóricometodológicos. Passo Fundo (RS): Universidade de Passo Fundo; 2001.

4. Coutinho MPL. Depressão infantil: uma abordagem psicossocial. João Pessoa (PB): Ed. Universitária; 2001.

5. Jodelet $D$, organizadora. Les représentation sociales. Paris: Presses Universitaires de France; 1988.

6. Minayo MC. O desafio do conhecimento. São Paulo (SP), Rio de Janeiro (RJ): Hucitec-Abrasco; 1996.

7. Moreira MIC. Gravidez e identidade do casal. Rio de Janeiro (RJ): Record; 1997.

8. Osorio LC. Adolescente hoje. Porto Alegre (RS): Artes Médicas; 1999.

9. Severino RL. Casais construindo seus caminhos: a terapia de casal e a família de origem. In: Prado LC, organizador. Famílias e terapeutas. Porto Alegre (RS): Artes Médicas; 1996. 10. Lewis M, Volkmar FR. Aspectos clínicos do desenvolvimento na infância e adolescência. Porto Alegre (RS): Artes Médicas; 1993.

11. Aberastury A, Knobel M. Adolescência normal. Porto Alegre (RS): Artes Médicas; 1992.

12. Codo W, coordenador. Educação: carinho e trabalho. Petrópolis (RJ): Vozes; 1999.

13. Paula DB. O olhar e a escuta psicológica desvendando possibilidades: o vínculo saudável entre a adolescente mãe e seu filho. [tese]. São Paulo (SP): Psicologia Social/ PUC; 1999.

14. Medrado B, Lyra J. A adolescência "desprevenida" e a paternidade na adolescência: uma abordagem geracional e de gênero. In: Ministério da Saúde (BR). Cadernos Juventude, Saúde e Desenvolvimento. Brasília (DF): Ministério da Saúde; 1999.

15. Medeiros M, Ferriani MGC, Munari DB, Gomes R. A sexualidade para o adolescente em situação de rua em Goiânia. Rev Latino-am Enfermagem 2001 março; 9(2):3541.

16. Stern D. O mundo interpessoal do bebê. Porto Alegre (RS): Artes Médicas; 1992. 